Check for updates

Cite this: RSC Adv., 2018, 8, 22042

Received 23rd May 2018

Accepted 11th June 2018

DOI: $10.1039 / c 8 \mathrm{ra0} 4407 d$

rsc.li/rsc-advances

\title{
A low-cost electrochemical thio- and selenocyanation strategy for electron-rich arenes under catalyst- and oxidant-free conditions $\uparrow$
}

\author{
Xing Zhang, (D) Chenguang Wang, (D) Hong Jiang (D) * and Linhao Sun (D)* \\ A low-cost and efficient thio- and selenocyanation strategy for electron-rich arenes has been developed \\ under constant-current electrolytic conditions in an undivided cell. This strategy is versatile for various \\ (hetero)aromatic compounds such as indole, pyrrole, aniline and anisole under mild conditions without \\ any catalyst or oxidant. Readily available salts $\mathrm{NH}_{4} \mathrm{SCN}$ and $\mathrm{KSeCN}$ are employed respectively as the sole \\ reagent.
}

\section{Introduction}

Organosulfur and organoselenium compounds, possessing broad biological and pharmaceutical activities, have been widely employed as important scaffolds for medicinal chemistry. Some representative examples are shown in Fig. 1, such as arylthioindole, ${ }^{1}$ albendazole ${ }^{2}$ and clioquinol derivatives. ${ }^{3}$ In synthetic methodology, thio- and selenocyanation have been paid much attention over the past decades because they are facile and efficient ways to incorporate sulfur and selenium elements into organic compounds.

Various methods for thiocyanation and selenocyanation of (hetero)aromatic systems have been established during the past few years. Lots of available methods of thiocyanation have combined thiocyanate salts with chemical oxidants such as $\mathrm{CAN},{ }^{4}$ oxone, ${ }^{5} \mathrm{DDQ},{ }^{6} \mathrm{Cu} / \mathrm{O}_{2},{ }^{7}$ hypervalent iodine reagents, ${ }^{8,9}$ $\mathrm{Mn}(\mathrm{OAc})_{3}{ }^{10} \mathrm{~K}_{2} \mathrm{~S}_{2} \mathrm{O}_{8},{ }^{11,12}$ etc. (Scheme 1a) Despite their efficiencies, these approaches suffered from many drawbacks and

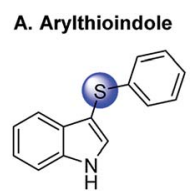

Potent inhibitor of tubulin polymerization

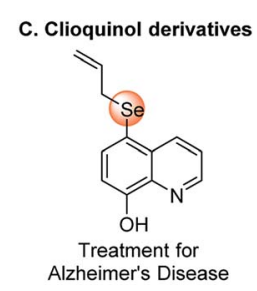

Inhibitor of cancer cell proliferation

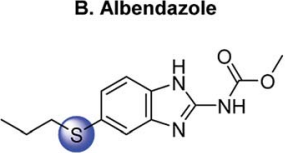

of biologically active organosulfur and organoselenium compounds.
Department of Chemistry, College of Science, Huazhong Agricultural University, Wuhan, 430070, P. R. China. E-mail: jianghong@mail.hzau.edu.cn; sunlinhao@ mail.hzau.edu.cn

$\dagger$ Electronic supplementary information (ESI) available. See DOI: $10.1039 / \mathrm{c} 8 \mathrm{ra} 04407 \mathrm{~d}$ limitations: harsh oxidizing experimental procedures, the use of stoichiometric oxidants and the bad impact of heavy-metal wastes. Recently photocatalysis ${ }^{13,14}$ and electrolysis ${ }^{15-17}$ have been proved to be eco-friendly alternative methods for oxidative aromatic thiocyanation (Scheme $1 \mathrm{~b}$ and c). Nevertheless, the costly photocatalyst or supporting electrolyte is required and the substrate scope is still narrow in these approaches. As for selenocyanation, only a few orthodox methods have been reported using triselenium dicyanide ${ }^{18,19}$ or combining KSeCN with a chemical oxidant $\left(\mathrm{CAN},{ }^{20} \mathrm{TBHP}^{21}\right)$ as selenocyating

Previous works

\section{Thiocyanation}

(a)

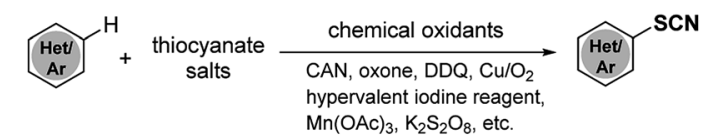

(b)

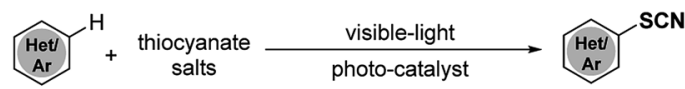

(c)
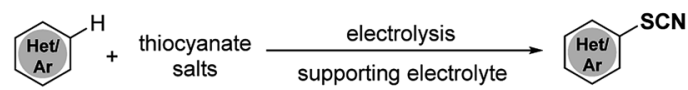

Selenocyanation

(d)

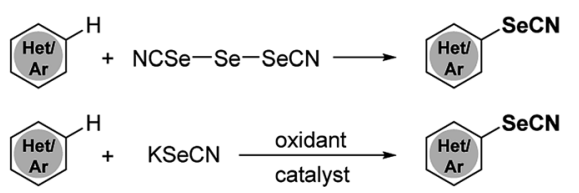

(e) catalyst
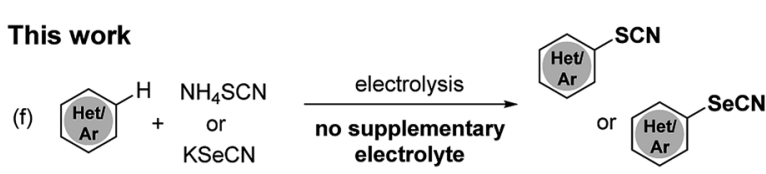

Scheme 1 Thio- and selenocyanation strategies for (hetero)aromatic compounds. 
reagent (Scheme 1d and e). Hence, the development of an efficient, eco-friendly and versatile strategy for thio- and selenocyanation is still desirable.

Recently, electrochemical functionalization of $\mathrm{C}-\mathrm{H}$ bonds becomes a hot research topic in organic synthesis. Adopting electron as "reagent" in place of stoichiometric amounts of oxidants or reductants, electrosynthesis has been recognized as an eco-friendly synthetic tool. ${ }^{22,23}$ As part of our continuous works on electrochemical (pseudo)halogenation reactions, ${ }^{24}$ herein we present an efficient, low-cost, catalyst- and oxidantfree approach for thio- and selenocyanation of electron-rich arenes using thio- or selenocyanate salts as the sole reagent under mild electrochemical condition (Scheme 1f).

\section{Result and discussion}

This work is initiated by optimizing the thiocyanation condition between $1 H$-indole (1a) and ammonium thiocyanate (2a) as a model reaction in an undivided cell. The desired thiocyanation product 3aa was obtained in $96 \%$ yield when the electrolysis was performed employing platinum as both anode and cathode under constant-current condition $j_{\text {anode }} \approx 5.33 \mathrm{~mA}$ $\mathrm{cm}^{-2}$ ) in an electrolyte solution of $\mathrm{CH}_{3} \mathrm{CN}$ containing $n \mathrm{Bu}_{4} \mathrm{NPF}_{6}$ as supporting electrolyte (Table 1, entry 1). Thiocyanation was totally suppressed without electric current (Table 1, entry 2) which led us to rule out the possibility of chemical thiocyanation between 1a and 2a. Atmospheric conditions led slight decrease to the yield of 3aa (Table 1, entry 3). To our delight, electrolysis could be conducted and resulted in an excellent yield without the supporting electrolyte salt $n \mathrm{Bu}_{4} \mathrm{NPF}_{6}$ (Table 1, entry 4). In this case excessive amount of $\mathrm{NH}_{4} \mathrm{SCN}$ served as both thiocyanating reagent and electrolyte, so the budget of electrolysis has been remarkably reduced. Moreover the introduction of protonic solvent, such as water, resulted in yield loss (Table 1, entry 5). The highest yield was obtained when electrolysis was performed at higher constant current $18 \mathrm{~mA}\left(j_{\text {anode }}\right.$

Table 1 Optimization of thiocyanation conditions ${ }^{a}$
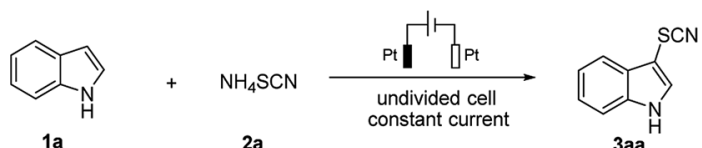

$1 \mathrm{a}$ Electrolysis conditions Yield $^{b}$

\begin{tabular}{lll} 
Entry & Electrolysis conditions & Yield $^{b}$ \\
\hline 1 & $\mathrm{CH}_{3} \mathrm{CN}, n \mathrm{Bu}_{4} \mathrm{NPF}_{6}(0.1 \mathrm{M}), 2 \mathrm{a}$ (1 equiv.), & $96 \%$ \\
& $12 \mathrm{~mA}, 4.5 \mathrm{~h}$ & \\
2 & Entry 1 but no electric current & 0 \\
3 & Entry 1 but open to air & $89 \%$ \\
4 & $\mathrm{CH}_{3} \mathrm{CN}, 2 \mathrm{a}(3 \mathrm{equiv}),. 12 \mathrm{~mA}, 4.5 \mathrm{~h}$ & $97 \%$ \\
5 & Entry 4 but $\mathrm{CH}_{3} \mathrm{CN} / \mathrm{H}_{2} \mathrm{O}(9: 1)$ as solvent & $78 \%$ \\
6 & Entry 4 but $18 \mathrm{~mA}, 3 \mathrm{~h}$ & $99 \%$
\end{tabular}

${ }^{a}$ Standard conditions: Pt anode, Pt cathode, $1 \mathrm{a}(0.5 \mathrm{mmol}), \mathrm{CH}_{3} \mathrm{CN}$ (10 $\mathrm{mL}$ ), room temperature, argon. ${ }^{b}$ The yield of 3 aa was determined by GC. $\approx 8 \mathrm{~mA} \mathrm{~cm}{ }^{-2}$ ) within $3 \mathrm{~h}$ (Table 1, entry 6 ). With these optimization studies, further exploration has been carried out using $\mathrm{NH}_{4} \mathrm{SCN}$ (3 equiv.) as the sole reagent in $\mathrm{CH}_{3} \mathrm{CN}$ at room temperature under constant current mode $\left(j_{\text {anode }} \approx 8 \mathrm{~mA}\right.$ $\mathrm{cm}^{-2}$ ).

With the optimized conditions in hand, we have tested the scope of this electrochemical thiocyanation strategy applying indoles derivatives and other electron-rich arenes as substrates (Scheme 2). Generally, electrochemical thiocyanation took place selectively at C3 position of indole derivatives; in the case of electron-rich arenes, the thiocyanation occurs at para or ortho position of arenes. Unsubstituted $\mathrm{N}-\mathrm{H}$ indoles containing an electron donating group showed better reaction efficiency (products 3ab-3ah 94-99\%) than those containing an electron withdrawing group (products 3ai-3ar 43-99\%). N-Methyl indoles afforded the thiocyanated products in excellent yield (products 3as-3au 91-99\%), however reaction could not occur when indole $\mathrm{N}-\mathrm{H}$ is protected by "Boc" or "Ts" group, which may due to their strong electron-withdrawing effect. Moreover, 7 -azaindole could also lead to product $3 a x$ with $64 \%$ yield. The substrate scope of this method is validated: other electron-rich arenes such as pyrrole, aniline and anisole, also showed a great efficiency and afforded the desired product with good to excellent yields (products $\mathbf{3} \mathbf{b a}-\mathbf{3} \mathbf{b j} \mathbf{7 2}-\mathbf{9 7 \%}$ ).
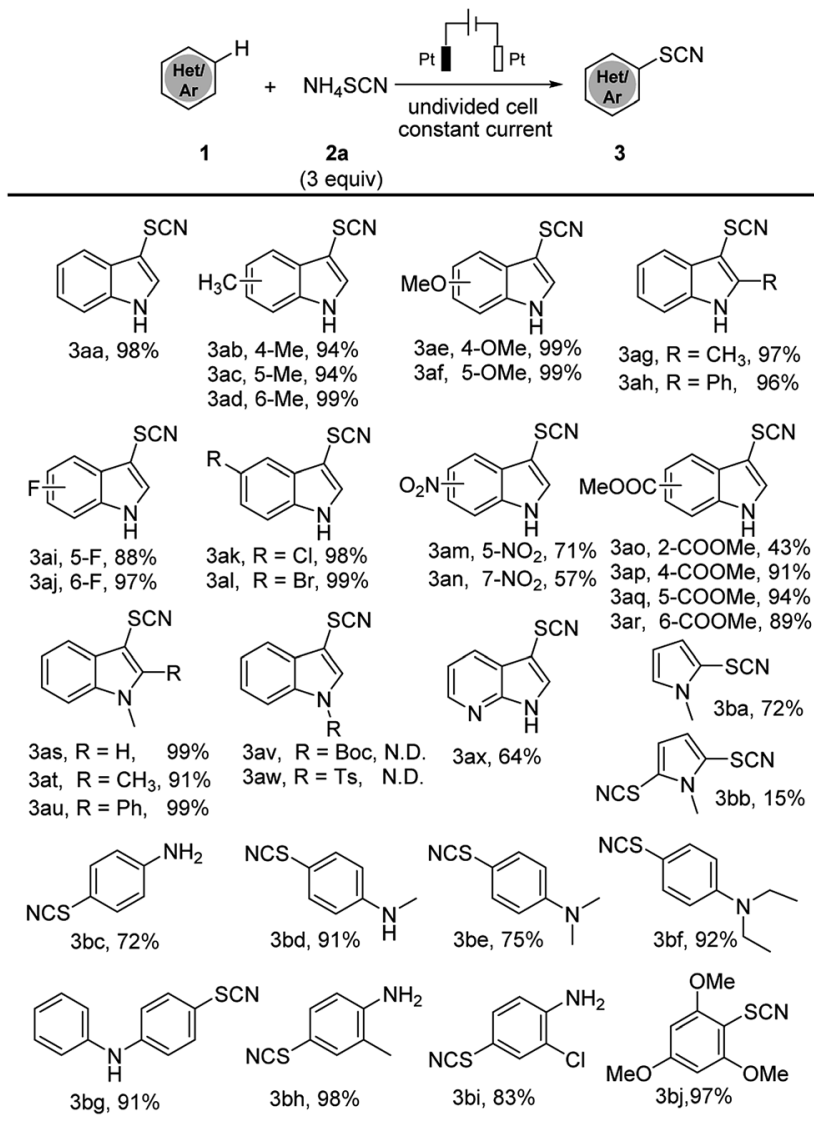

Scheme 2 Substrate scope of electrochemical thiocyanation. Standard conditions: Pt anode, Pt cathode, constant current $=18 \mathrm{~mA}, 1$ (0.5 $\mathrm{mmol}), 2 \mathrm{a}(1.5 \mathrm{mmol}), \mathrm{CH}_{3} \mathrm{CN}(10 \mathrm{~mL})$, room temperature, argon, $3 \mathrm{~h}$, isolated yields are shown. N.D. = not detected. 

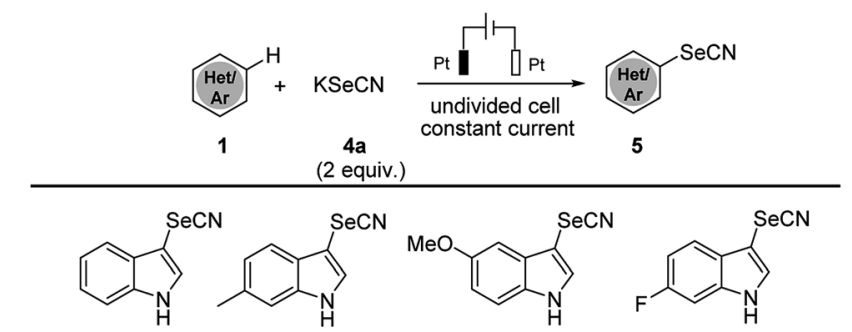

(a), 94\%

$5 \mathrm{ab}, 80 \%$

5ac, $70 \%$

5ad, $73 \%$

5ai, 83\%<smiles>Cc1ccc2[nH]cc([Se]C#N)c2c1</smiles>
5af, $77 \%$
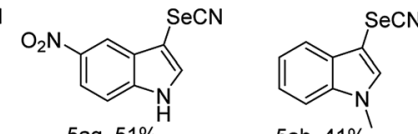

5ah, $41 \%$

$$
\text { 5ag, } 51 \%
$$<smiles>CN(C)c1ccc([Se]#N)cc1</smiles>

5ak, 52\%

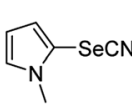

5aj, N.D.

Scheme 3 Substrate scope of electrochemical selenocyanation. Standard conditions: Pt anode, Pt cathode, constant current $=18 \mathrm{~mA}$, $1(0.5 \mathrm{mmol}), 4 \mathrm{a}(1 \mathrm{mmol}), \mathrm{CH}_{3} \mathrm{CN}(10 \mathrm{~mL})$, room temperature, argon, $3 \mathrm{~h}$, isolated yields are shown. N.D. = not detected.

The success of electrochemical thiocyanation of electronrich arenes led us furtherly to explore the electrochemical selenocyanation. We continued our investigations applying the analogous condition as the electrochemical thiocyanation. By treating $1 \mathrm{H}$-indole 1a with $\mathrm{KSeCN}$ ( 2 equiv.) as the sole reagent in $\mathrm{CH}_{3} \mathrm{CN}$ under constant-current mode, the corresponding selenocyanated product 5aa could be electrogenerated in $94 \%$ yield (Scheme 3). We summarized the substrate scope of electrochemical selenocyanation in Scheme 3. Electron-rich indole derivatives furnished the target products in good yields (Scheme 3 , products 5aa-5ac). Electron-deficient indole derivatives such as 6-fluoro-, 5-fluoro, 5-chloro and 5-nitroindole could also lead to selenocyanated products in moderate to good yields (products 5ad-5ag 51-91\%). When $N$-methylindole was used as a substrate, the selenocyanation yield was dramatically dropped to $41 \%$ (product 5ah). Interestingly, introducing a methyl group at the C-2-position of the $\mathrm{N}$-methylindole afforded the selenocyanated product 5ai in $83 \%$ yield, which may due to the electron-donating effect. Unfortunately, the electrochemical selenocyanation could not work in this condition, only the aniline compounds could afford selenocyanated product in moderate yields (product 5ak 52\%).

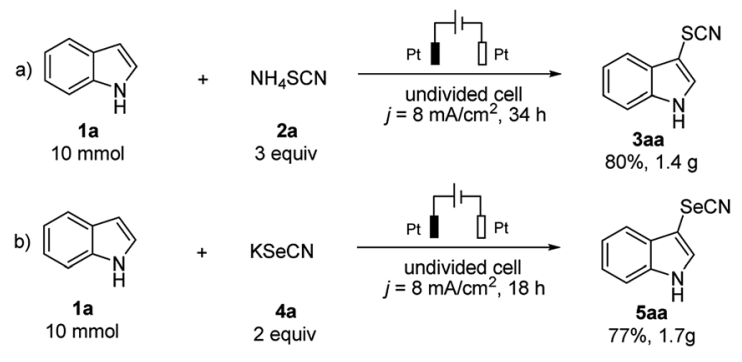

Scheme 4 Gram-scale synthesis.

The scalability of this approach was evaluated by performing the electrochemical thio- and selenocyanation of $1 \mathrm{H}$-indole on a gram-scale. The electrolysis of $10 \mathrm{mmol}$ substrate led to $80 \%$ isolated yield of 3aa (Scheme $4 \mathrm{a}$ ) and $77 \%$ for $5 \mathbf{a a}$ (Scheme $4 \mathrm{~b}$ ). Moreover, compared with the traditional electrochemical approach, ${ }^{\mathbf{1 6 , 1 7 , 2 5}}$ the double role of thio- or selenocyanated salt in this approach (as both SCN/SeCN source and supporting electrolyte) has remarkably reduced the budget of electrolysis, showing a great potential on industrial applications.

In order to gain insights into the mechanism of the electrolytic process, we performed the radical inhibition experiments ${ }^{26,27}$ to verify the existence of radical intermediates. Since the oxidation potential of TEMPO is higher than XCN anion ( $\mathrm{X}$ $=\mathrm{S}$, Se, see ESI $\uparrow$ for the voltammograms), it cannot be oxidized before XCN anion, so it could inhibit XCN radical during electrolysis. When an excess amount of TEMPO was added in the reaction between 1a and 2a or $4 \mathbf{a}$ under the standard electrolytic conditions, thio- and selenocyanation were totally suppressed (Scheme 5a). These results led us to confirm the presence of radical intermediates during electrolysis. In fact, literature reports ${ }^{\mathbf{1 6 , 1 7 , 2 2 , 2 5}}$ have already demonstrated a mechanism via electrophilic aromatic substitution for the similar transformation. A putative reaction mechanism was proposed as illustrated in Scheme $5 \mathrm{~b}$.

In the first step, thio- or selenocyanate anion gets oxidized by a single-electron-transfer process at the anode to generate the corresponding radical. $(\mathrm{XCN})_{2}$ could be formed through radical coupling, which could furtherly generate the electrophile $\mathrm{XCN}^{+}$. After the electrophilic attack, the hydroindole cation intermediate can then release a proton to give the desired product. Concomitant cationic reduction involves the reduction of $\mathrm{H}^{+}$to $\mathrm{H}_{2}$, which can be confirmed by the observation of gas release at the cathode surface during electrolysis. Another one-electron
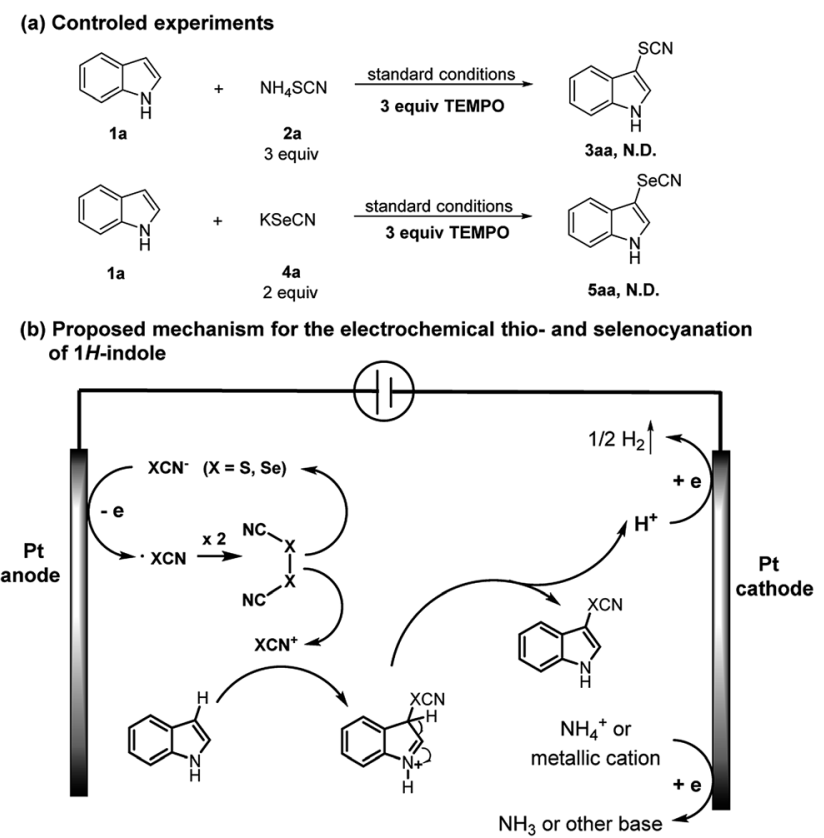

Scheme 5 Mechanistic investigations and proposed mechanism. 
reduction may concern the cation from electrolyte $\left(\mathrm{NH}_{4}{ }^{+}\right.$or $\left.\mathrm{K}^{+}\right)$ leading the accumulation of base during electrolysis.

\section{Conclusions}

In summary, a facile, efficient and low-cost electrochemical thio- and selenocyanation strategy has been developed which enables $\mathrm{C}-\mathrm{S}$ and $\mathrm{C}-\mathrm{Se}$ bond formation under catalyst- and oxidant-free conditions. Various electron-rich arenes exhibited great efficiencies for this transformation. Importantly, the reaction can be performed on a gram scale with good reaction efficiency and the sole necessary reagent is readily available thio- or selenocyanated salts. These advantages encourage us to have prospect towards industrialization. Further studies on the electrochemical $\mathrm{C}-\mathrm{H}$ functionalization are underway in our laboratory.

\section{Experimental}

General procedure for thio- and selenocyanation of electronrich arenes

In an oven-dried undivided four-necked bottle $(25 \mathrm{~mL})$ equipped with a stir bar, electron-rich arene ( $0.5 \mathrm{mmol}), \mathrm{NH}_{4} \mathrm{SCN}(1.5$ $\mathrm{mmol})$ or $\mathrm{KSeCN}(1.0 \mathrm{mmol})$ and $\mathrm{CH}_{3} \mathrm{CN}(10 \mathrm{~mL})$ were combined and added. The bottle was equipped with platinum plate $\left(1.5 \times 1.5 \mathrm{~cm}^{2}\right)$ as both the anode and cathode and was then charged with argon. The reaction mixture was stirred and electrolyzed at a constant current of $18 \mathrm{~mA}$ under room temperature for $3 \mathrm{~h}$. When the reaction was finished, the solvent was removed with a rotary evaporator. The pure product was obtained by column chromatography on a silica gel column using petroleum ether: ethyl acetate $=10: 3$.

\section{Conflicts of interest}

There are no conflicts to declare.

\section{Acknowledgements}

This work was financially supported by the National Natural Science Foundation of China (No. 21502058) and the Fundamental Research Funds for the Central Universities (No. 2662015QC031).

\section{Notes and references}

1 G. De Martino, G. La Regina, A. Coluccia, M. C. Edler, M. C. Barbera, A. Brancale, E. Wilcox, E. Hamel, M. Artico and R. Silvestri, J. Med. Chem., 2004, 47, 6120-6123.

2 Q. Guan, C. Han, D. Zuo, M. a. Zhai, Z. Li, Q. Zhang, Y. Zhai, X. Jiang, K. Bao, Y. Wu and W. Zhang, Eur. J. Med. Chem., 2014, 87, 306-315.
3 Z. Wang, Y. Wang, W. Li, F. Mao, Y. Sun, L. Huang and X. Li, ACS Chem. Neurosci., 2014, 5, 952-962.

4 V. Nair, T. G. George, L. G. Nair and S. B. Panicker, Tetrahedron Lett., 1999, 40, 1195-1196.

5 G. Wu, Q. Liu, Y. Shen, W. Wu and L. Wu, Tetrahedron Lett., 2005, 46, 5831-5834.

$6 \mathrm{H} . \quad$ R. Memarian, I. Mohammadpoor-Baltork and K. Nikoofar, Can. J. Chem., 2007, 85, 930-937.

7 H. Jiang, W. Yu, X. Tang, J. Li and W. Wu, J. Org. Chem., 2017, 82, 9312-9320.

8 F. Wang, X. Yu, Z. Qi and X. Li, Chem.-Eur. J., 2016, 22, 511516.

9 J. Yadav, B. Reddy and B. Murali Krishna, Synthesis, 2008, 3779-3782.

10 X.-Q. Pan, M.-Y. Lei, J.-P. Zou and W. Zhang, Tetrahedron Lett., 2009, 50, 347-349.

11 D. Yang, K. Yan, W. Wei, G. Li, S. Lu, C. Zhao, L. Tian and H. Wang, J. Org. Chem., 2015, 80, 11073-11079.

12 T. B. Mete, T. M. Khopade and R. G. Bhat, Tetrahedron Lett., 2017, 58, 415-418.

13 W. Fan, Q. Yang, F. Xu and P. Li, J. Org. Chem., 2014, 79, 10588-10592.

14 S. Mitra, M. Ghosh, S. Mishra and A. Hajra, J. Org. Chem., 2015, 80, 8275-8281.

15 A. Gitkis and J. Y. Becker, Electrochim. Acta, 2010, 55, 58545859.

16 L. Fotouhi and K. Nikoofar, Tetrahedron Lett., 2013, 54, 29032905.

17 V. A. Kokorekin, V. L. Sigacheva and V. A. Petrosyan, Tetrahedron Lett., 2014, 55, 4306-4309.

18 A. V. Kachanov, O. Y. Slabko, O. V. Baranova, E. V. Shilova and V. A. Kaminskii, Tetrahedron Lett., 2004, 45, 4461-4463.

19 S. Redon, A. R. Obah Kosso, J. Broggi and P. Vanelle, Tetrahedron Lett., 2017, 58, 2771-2773.

20 N. Vijay, A. Anu and G. G. Tesmol, Eur. J. Org. Chem., 2002, 2363-2366.

21 N. Muniraj, J. Dhineshkumar and K. R. Prabhu, ChemistrySelect, 2016, 1, 1033-1038.

22 M. Yan, Y. Kawamata and P. S. Baran, Chem. Rev., 2017, 117, 13230-13319.

23 R. Francke and R. D. Little, Chem. Soc. Rev., 2014, 43, 24922521.

24 L. Sun, X. Zhang, Z. Li, J. Ma, Z. Zeng and H. Jiang, Eur. J. Org. Chem., 2018, DOI: 10.1002/ejoc.201800267.

25 V. A. Kokorekin, R. R. Yaubasarova, S. V. Neverov and V. A. Petrosyan, Mendeleev Commun., 2016, 26, 413-414.

26 T. Vogler and A. Studer, Synthesis, 2008, 2008, 1979-1993.

27 P. Wang, S. Tang, P. Huang and A. Lei, Angew. Chem., Int. Ed., 2017, 56, 3009-3013. 